SHS Web of Conferences 24, 02016 (2016)

DOI: $10.1051 /$ shsconf/ 20162402016

(C) Owned by the authors, published by EDP Sciences, 2016

\title{
Research and practice on the training mode of the core competence about the application-oriented electrical information engineering undergraduate
}

\author{
Jing Bai* \& Yanxia Song \\ College of Electrical Information Engineering, Beihua University, Jilin, Jilin, China
}

\begin{abstract}
Nowadays, the method of cultivating talents in colleges and universities is out of line with the social demand on the training goal of electrical information talents in local application-oriented colleges and universities. To solve this problem, this paper put forward the concept of "five view" about the engineering education (practice) and the engineering core competence, systematically solved the key problems such as the training mode of application-oriented undergraduate, positioning, teaching system, training methods, evaluation methods and criteria, thus making that the application-oriented undergraduate students can meet the needs and target of enterprise after graduation.
\end{abstract}

Keywords: local applied undergraduate; engineering education; engineering core competence (core type); production line; training method of personnel

\section{INTRODUCTION}

According to the situation in the provincial and local application-oriented personnel training, in order to adapt to the requirements of the, most people have to meet as soon as possible to adapt to the new situation of employment market changing the role of the practical problems. This paper puts forward the core competence of cultivating application-oriented engineering talents to promote the deepening reform of the education and teaching, which helps application-type undergraduate students can meet the need and target of enterprises after graduation in view of the talents' training target of application-type colleges and universities and the demand of enterprise towards talents. The students in local colleges and universities are engaged in the actual situation such as the actual situation of project development, technical support, technical management, equipment maintenance and so on under the premise of ensuring the basic requirements of engineering talents. In order to meet the social needs, respect students' personality development, innovation spirit and practical ability training, and the reform research and practice of the core competency

*Corresponding author: jlbyj@163.com training mode of electrical information engineering.

\section{RESEARCH SITUATION, LEVEL AND DEVELOPMENT TREND OF DOMESTIC AND FOREIGN RESEARCH}

Take the foreign training mode of talents as an example, and the models in United States and Germany are more successful. One of the characteristics of American higher education is the high-level development and high educational level of public with "generalist (namely, the "encyclopedia-type" educational mode, recently it is stressed from the aspects such as the "practical application first", the outstanding engineering system and practical characteristics, practical results and improve the competitiveness of its industrial products in the world.)The goal of engineering education of undergraduate in Germany, the newly industrialized country is to train trained engineers through using the educational mode "essence of life". The undergraduate education in China is mainly affected by two models to some extent, although having cultivated myriads of scientists, engineers and different kinds of specialized talents. China is a developing country, affected by the "specialist" education mode 
of the former Soviet Union and has achieved certain results under the condition of planned economy. At present, China's rapid economic development has made its higher education which is transformed from the meritocracy to the popular education, and the contradiction exists between the training mode and the social demand. The engineering education in China's entire higher education system is about $80 \%$ of the survey data. The reform of China's industrial technology and the development of the science and technology is successful. Requirements from the actual situation of our country are to solve the problem of personnel training system.

Through social investigation, in view of the local comprehensive university engineering personnel training goal, ability orientation, social demand for talents, especially on the basis of the theoretical research and practice results of the early education reform, to reach the following consensus:

1) The enterprise has a huge demand for the application type talents in Colleges and universities, which has the characteristics of "strong practical ability, quick start, development potential and wide knowledge".

2) The company's expectations for the application type of talent are: to solve practical problems in the first line of production.

3) The ability of the enterprise to the applied talents is more concerned about the engineering application ability in the process of "technology integration, technology transfer, technology implementation"

4) The enterprise has a high comprehensive quality of talents with high comprehensive quality, which is very eager to have a strong sense of professionalism, a sense of responsibility, a strong sense of teamwork, a strong sense of teamwork and learning ability.

By the development of China's industrial and engineering technology, the practical need to determine the higher engineering education in China should be trained and trained engineers as the basic objective is the objective needs. Application oriented undergraduate and research is different, the training of engineering and technical personnel is mainly engaged in the production of the first line of the design, manufacturing, operation, construction, testing, technical guidance and other work, focusing on production line. Therefore, the key problem is to find the social (enterprise) needs to meet the needs of school personnel training and the corresponding engineering personnel training concept, training system, training methods, methods and means, evaluation and assessment criteria.

\section{ENGINEERING CORE ABILITY OF ELECTRICAL INFORMATION PERSONNEL TRAINING MODE}

Renewing educational ideas: the first academic re- sponsibility of every teacher is to promote the comprehensive development of man, to meet the needs of the society and the employing unit. Learn project in an active, practical, and organic connection between courses. The integration of knowledge, ability, quality training, life and work and the combination of teaching and learning, the theory of teaching, experiment and practice teaching and innovation.

The first time to put forward the concept of "Five", the system has solved the application oriented personnel training of educational ideas, teaching system, training methods, methods and means, evaluation and assessment standards and other related issues to achieve the goal of the construction of the core type of electrical and information personnel training.

\subsection{Education idea - quality view of engineering education}

According to the characteristics of engineering education practice, the main goal of engineering education is to cultivate the ability of knowledge, and to break the teaching mode and teaching mode, which is the "ability training mode", and the most advanced and systematic knowledge is not the main. The embodiment of the quality of knowledge and ability, engineering education of the core ability of the key lies in the application of knowledge, and transformed into the ability to solve practical problems.

\subsection{Ability to develop a mode of dual master}

Taking "teacher as the leading, taking the students as the main body" double main mode, taking ability training as the center, breaking the teaching mode of knowledge design in accordance with the subject system, changing "knowledge imparting type" as "ability training type". Each teaching link to implement the industry's ability to meet the requirements of industrial quality of engineering personnel, pay attention to practice, regression engineering, we can directly refer to the industrial demand, to push back to the syllabus, teaching plan and curriculum, through each class, each module. The real need to solve the problem and the project is students learn content from the first line of business, the contents of these elements not only to contact with the discipline, but also with the industrial market, so that the development of disciplines and industry development, the market development of basic coordination.

The establishment of engineering core ability of electrical and information personnel training system are to make the need for enterprises to achieve seamless.

We can obtain the goal due to enterprise production line needs, through the social and the use of external quality monitoring as a detector to adjust the training program, and then through the school's supervision group, peer and student information quality monitor- 
SSHE 2015

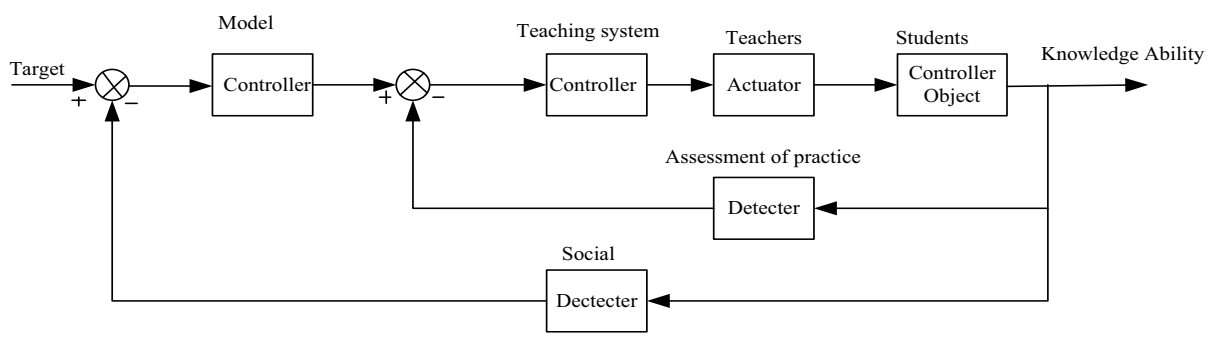

Figure 1. Engineering core competence electrical information talent cultivation system

ing. As the carrier to project and with a series of cases of teaching material and experimental equipment, a project background of teachers and students to meet the requirements of the production line of knowledge, ability and quality, and business needs to achieve seamless. The teaching system block diagram is shown in figure 1.

\subsection{Cultivation way - the educational view of engineering resources}

"Communication with our engineering colleges are mostly closed schools, the lack of industry and social interaction, industry of education objectives, education process, education method is not much of an impact, what's more engineering university teachers, most are from school to school, not lack of high degree, but the lack of industry experience and industry communication, schools and teachers do not understand their" customer ",so that , the industry needs, but to their" customer "industrial enterprises" production "talent", "product" of course to be their "customer", so that, the industry enterprise identity, accept, it is difficult to meet the business needs. Thus, the emergence of the students cannot find a job; on the other hand, the enterprise does not recruit students in a dilemma". The concept of education of engineering resources is based on the application oriented talents, the characteristics of the service in the local, the industry, and to create a real engineering environment to cultivate students' engineering consciousness. Professional basic experimental equipment is the embodiment of the open type, component, and general of the industrial field device. The experimental equipment of the professional direction is the product type, integration and typical of the industrial field equipment. The workplace environment is introduced into the whole process of education. The theory foundation is closely related to the practical application, strengthening the practical teaching.

\subsection{Methods and means - effective view}

The traditional way of teaching in the listening teaching is that teachers teach knowledge of teaching system step-by-step, students listen to learn, as long as the "pass" can be. The entry point of the local college engineering education should be "doing the teaching, doing the middle school, doing the middle school, thinking and learning": Combined with engineering object, application background of the project (conception, design, implementation and operation) teaching method; improve the heuristic, case teaching method; exploration and practice: inquiry based learning method (design work); exploration and practice structure optimization of the KM teaching method (Chapter - Section - knowledge point - note - Chapter - Chapter), heuristic, discussion, case, inquiry, interactive, learning, self-learning, online learning and cooperative learning methods, etc..

Teaching means, on the basis of traditional writing teaching, the teaching and research achievements, achievements in scientific research, network curriculum, multimedia teaching resources, MOOC, applied to teaching, the rational use of multimedia means, to increase the students' perceptual knowledge, increase the amount of information in teaching. The use of network teaching resources, combined with the characteristics of students like the use of the network, the classroom, exercises, communication, extended to the network, open network teaching resources, etc.

\subsection{Evaluation method and evaluation criteria - a comprehensive evaluation of process dynamics}

In the evaluation method and evaluation standard and other management mechanism, the design of the quality objectives and standards, teaching organization and implementation of subsystem, teaching process monitoring subsystem, teaching quality information collection and feedback subsystem, four of the process and dynamic comprehensive evaluation of the sub system.

Ability training as the core of engineering ability core personnel training to focus on the assessment of students' ability to apply knowledge, analyze problems and solve problems, engineering application ability. Engineering courses using uncoiled or unwinding + large operations, application of course written examination and operation, professional basic course is based on the use in teaching and examination separated. All examinations are used A, B volumes; additional comprehensive practice course group, graduation design are encouraged to do real. 


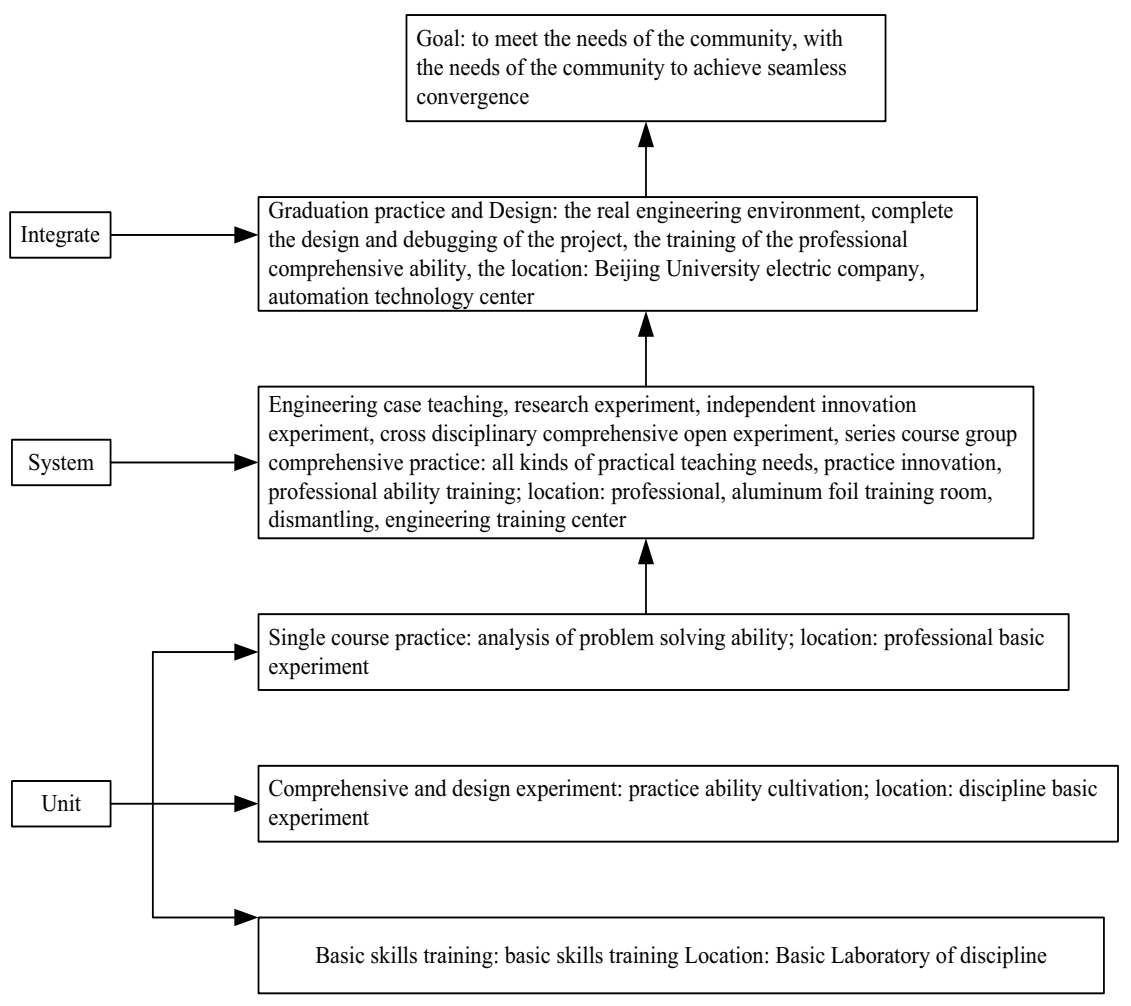

Figure 2. The 2 levels of personnel training of electrical information

\section{TALENTS TRAINING WAY OF ELECTRICAL INFORMATION WITH ENGINEERING CORE ABILITY}

The idea of talent training with engineering core ability is to meet the requirements of the industry and to meet the requirements of the industry's quality of engineering talents and to meet the requirements of the industry. Students learn content from the first line of business, which is the real need to solve the problem and the project. The contents of these elements are not only to contact with the discipline, but also with the industrial market, so that the development of disciplines and industry development, the market development of basic coordination.

Through the following five aspects, students' ability cultivation to reflect the laws of cognition, according to the unit to the system to the production practice, system integration, from the point to the principle of line and surface, progressive approach to the building.

(1) Course experiment: theory relation practice, practice theory

(2) To focus on the practice of the target as the carrier, the cultivation of practical ability

(3) The curriculum group is integrated, which depends on the specific project, training professional ability

(4) Combined with the actual production, the engi- neering practice, construction environment.

(5) Create the base of students extracurricular innovation, ability and quality. The 2 levels of personnel training of electrical information is shown in figure 2.

Through the above construction, the units of teaching equipment will be formed in the practice of industrial equipment, electronic products, the system of teaching equipment, industrial equipment, electronic products, industrial equipment, industrial equipment, industrial equipment, electronic products, system integration of 6 modules as the basic structural elements of electrical information. According to the unit (micro), system (meso), system integration (macro) three levels, the construction of electrical and information engineering is teaching system. In the micro level of the unit, it is reflected in the middle school, in which the middle level of the system is reflected in the middle school and it embodies the unity of knowledge, ability and quality.

\subsection{Micro level}

Micro level correspondence course (unit) project, which is the primary $\mathrm{CDIO}$, which corresponds to professional education, only need to use Billing Division of the knowledge, suitable for on the specific professional foundation courses or practice ability training. 


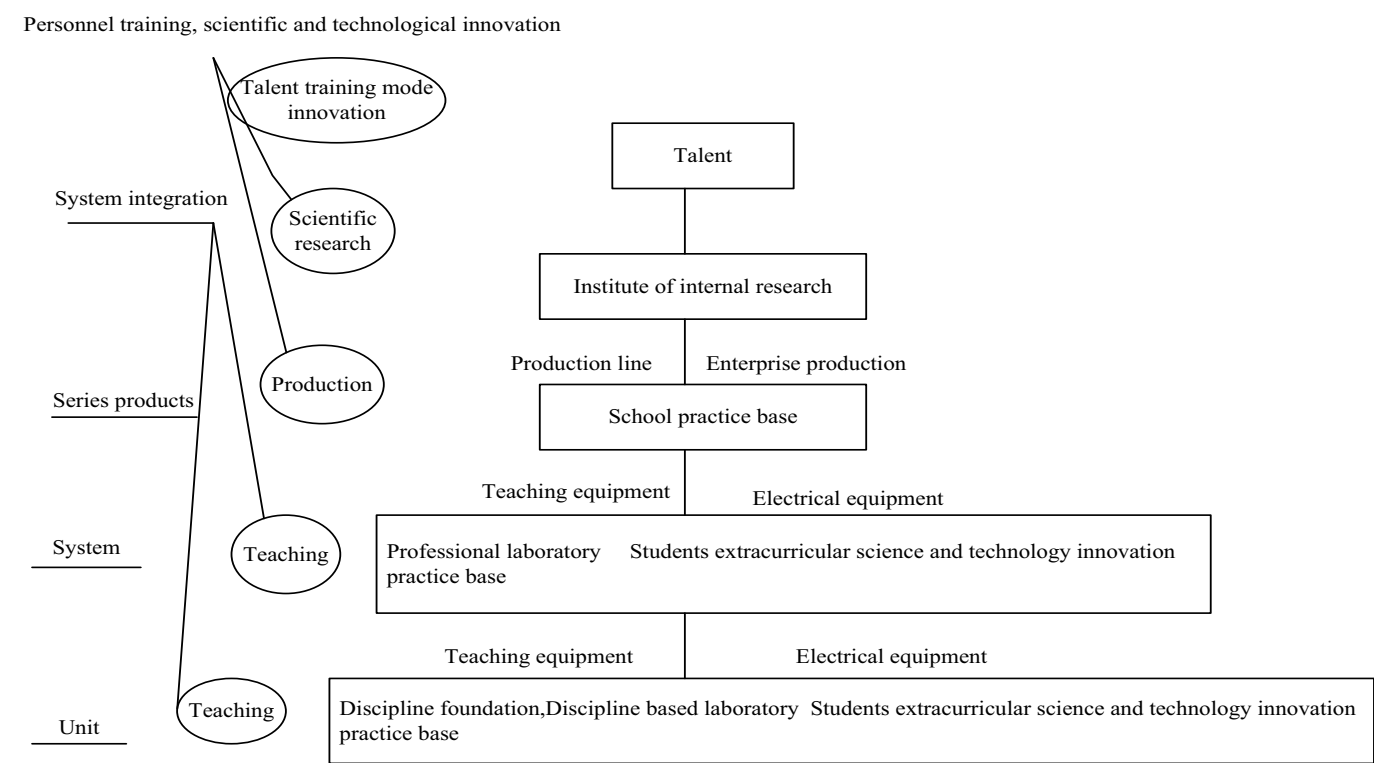

Figure 3. The relationship between the 3 aspects of the cultivation of talents and the integration of the teaching and production

The micro level is based on the "discipline foundation, professional basic laboratory" as the foundation to build the teaching equipment, electrical equipment, electronic product unit practice base, the purpose is basic skills training, practical ability training, analysis and problem-solving skills training, for the medium level foundation.

\subsection{Meso level}

The meso level correspondence course group, comprehensive courses of engineering activities. This is the intermediate CDIO, which corresponds to the professional education in some of the curriculum knowledge, local design skills. The corresponding course requires the use of a number of related courses of knowledge.

The medium level is to build a teaching equipment level system based on the basis of "all professional laboratories". The purpose is to understand the mechanism of the theory to understand the system design specification, process, principle and composition and to lay the foundation for the macro level.

\subsection{Macro level}

To achieve seamless integration of personnel training and business needs, macro level corresponding professional course group and system integration projects, reflecting engineering teaching, which is advanced CDIO. System integration projects need to use the knowledge to solve practical engineering problems, such as graduation design and other teaching projects, so that students have the ability to design the system.
On the macro level, the enterprise level production practice base (dynamic) is built on the basis of "practice base" in practice. The purpose is to understand the various parts of the enterprise production, realize the engineering quality cultivation and master the design specification, process, principle and composition of the system. The relationship is shown in figure 3 .

\section{PRACTICAL EFFECT}

In the past five years, we have made great progress in the cultivation of talents through the practice of the electrical information specialty of our school. During the period of school students by the variety of forms, and extends to the practice of the whole program hands-on ability, independent learning ability training and ability training as the goal of the teaching practice, achieved the integration of knowledge, ability and quality to create a "Challenge Cup competition", "electronic design contest" and "business plan competition" students' characteristics of the brand and achieved better personnel training achievements, employment rate has been maintained at above $90 \%$, increasing levels of employment, ability to endure hardship, started fast, precise enough stamina "characteristics, by the employing unit from.

\section{CONCLUSION}

The research and practice on application-oriented undergraduate engineering ability core type of the application-oriented undergraduate engineering is put 
forward. The quality of engineering education, the ability of the double main model, the concept of engineering resources, the method and the method of effective and the process of the comprehensive evaluation of the students in the active, practical, curriculum, the integration of knowledge, ability and quality; Meet the needs of personnel training and business needs of the seamless convergence and achieved good results.

\section{REFERENCES}

[1] Mingyi Wang. 2014. Responsible for the mission of the times to create Chinese higher education. Applied university. China Higher Education, 21: 34-37.

[2] Fang Ye. 2014. Highlights the excellence of local colleges and universities to promote the cultivation of applied talents. China's Higher Education, 15, 16:36-37.

[3] Enjing Li. 2011. Survey and analysis of laboratory safety management in colleges and universities. 28(2): 198-200.

[4] Min Liu. 2007. The problems and Countermeasures of higher engineering education personnel training mode. Journal of Yancheng Institute of Technology (Social Science Edition), (1): 79-83.

[5] Gaofeng Zhu. 2003. The reform and development of engineering education in China in the new century, (1):3-9.

[6] Mingxian Shi. 2002. For the United States engineering education reform in twenty-first Century. Chinese University Teaching, (10): 39-41.

[7] Jianhua Wang \& Hong Zhao. 2005. Research on the reform of higher engineering education. Journal of Shaoyang University, (4): 139-141

[8] Zhongbing Cai. 2009. The quality improvement strategy of Applied Engineering Talents Cultivation in local colleges and universities. China Electric Power Education, (9): 11-13

[9] LijunYang. 2014. Research and practice of application oriented undergraduate talent training model for electrical engineering and automation. Journal of Liaoning Institute of Science and Technology. 06-15.
[10] Jun Cui. 2011. Return to Engineering Practice: China's Higher Engineering Education Curriculum Reform Research. Nanjing University. 12, 30.

[11] Xiaojun Li. 2009. Comparative Study on the Cultivation of Undergraduate Technical Education Personnel. East China Normal University. 05, 01.

[12] Wanzhong Lei, \& Baojie Ji. 2011. Research and exploration of constructing. Laboratory Teaching System of Electronic Information Engineering. 06,15.

[13] Xiao Yu. 2012. Research on the Development of Engineering Practice Ability for Industry Demand. Zhejiang University. $03,01$.

[14] Jing Shan Wu. 2014. Research on Engineering Education Mode Based on Integration. Zhejiang University. $11,01$.

[15] Greco RS, \& Donetz AP. 1982. Career development of resident in university and independent training programs: the influence of special training fellowships, type of practice, specialization, and research. Pubmed. 02.

[16] Louis G, castonguag, Aaron L, pincus, Andrew A, \& McAeavey. 2015. Practice research network in a psychology training clinic: Building an infrastructure to foster early attachment to the scientific-practitioner model. Taylor \& Francis. 01.

[17] Ellis Michelle C, Dhungel Birat, \& Weerasinghe Roshanthi. 2011. Trends in research time, fellowship training, and practice patterns among general surgery graduates .PubMe. 04.

[18] Ried Karin, Montgomery Brett, \& Stocks Nigel P. 2008. General practice research training: impact of the Australian Registrar research Workshop on research skills, confidence, interest and involvement of participants. PubMe. 02.

[19] Dolor Rowena, \& Smith Peter C. 2008. Institutional review board training for community practices:advice from the Agency for Health Care Research and Quality Practice-Based Research Network listserv. PubMe. 04.

[20] Rajesh Pillania. 2014. Green management: The state of practice, research, teaching, training and consultancy in lndian business schools. Emerald. 02.

[21] Patrick McCrystal. 2009. George Wilson Social Work Education. Research Training and Professional Social Work Education: Developing Research-Minded Practice. Taylor \& Francis. 08. 